Alice Maria Melville Paiva Della LIBERA ${ }^{1}$

Eduardo Harry BIRGEL ${ }^{1}$ Sandra Satiko KITAMURA 2,3

Andrea Mello Franco

ROSENFELD ${ }^{4}$

Ênio MORI ${ }^{1}$

Cristina de Oliveira

Massoco-Salles GOMES ${ }^{3}$

Wanderley Pereira de

ARAÚJO ${ }^{1}$

Correspondência para: ALICE MARIA MELVILLE PAIVA DELLA LIBERA

Departamento de Clínica Médica Faculdade de Medicina Veterinária Universidade de São Paulo Av. Prof. Dr. Orlando Marques de Paiva, 87 05508-000 - São Paulo - SP dellalibera@fmvz.usp.br

Recebido para publicação: 02/08/2004 Aprovado para publicação: 23/08/2005

\title{
Macrófagos lácteos de búfalas hígidas: avaliações da fagocitose, espraiamento e liberação de $\mathrm{H}_{2} \mathrm{O}_{2}$
}

\author{
1- Departamento de Clínica Médica da Faculdade de Medicina Veterinária e \\ Zootecnia da Universidade de São Paulo, São Paulo - SP \\ 2 - Faculdade de Medicina Veterinária da Universidade Paulista, São Paulo - SP \\ 3 - Faculdade de Medicina Veterinária da Universidade Anhembi Morumbi, \\ São Paulo - SP \\ 4 - Laticínio Morro da Pedra
}

\section{Resumo}

O presente estudo teve por objetivo avaliar funcionalmente os macrófagos lácteos "nonelicited” presentes por meio de testes de fagocitose, espraiamento e liberação de peróxido de hidrogênio. Foram colhidas 56 amostras de leite de 15 búfalas hígidas e mensuradas a contagem de células somáticas total e diferencial, a viabilidade celular, os testes de fagocitose, de espraiamento e a liberação de peróxido de hidrogênio. Dessas variáveis obteve-se respectivamente média de 14.500 cél $/ \mathrm{mL}$ de leite; com mediana de 4,33\% de linfócitos e médias e desvios padrão de 50,77\% + 18,28 de células da série monócito/ macrófago e 32,13\% $\pm 19,27$ de polimorfonucleares. A viabilidade das células na suspensão foi $66,8 \%+15,8$ e os índices de fagocitose e espraiamento foram $30,1 \% \pm 16,9$ e 58,5\% $\pm 13,3$. Não houve diferença entre a liberação de $\mathrm{H}_{2} \mathrm{O}_{2}$ espontânea e induzida por PMA. Concluiuse que os macrófagos presentes no leite de búfalas hígidas e espraiaram significativamente, além de apresentarem correlação com outro marcador de ativação celular, no caso, a liberação de peróxido de hidrogênio; mais da metade dos macrófagos aderidos fagocitaram partículas de zymosan; os fagócitos mantêm sua capacidade de liberar peróxido de hidrogênio, espontaneamente ou não, em grau máximo, com uma significativa variação entre amostras.

\section{Introdução}

Os mecanismos celulares são fundamentais para a defesa da glândula mamária. Apesar de atribuir-se aos polimorfonucleares neutrófilos a maior responsabilidade na proteção da glândula mamária frente à ação dos microrganismos, esses necessitam da ação prévia dos mononucleares monócitos/macrófagos, mantendo-se a delicada inter-relação que regeria os mecanismos imunes ${ }^{1,2}$.

Aos macrófagos das secreções lácteas foram atribuídas funções consideradas como acessórias, secretórias, efetoras e reguladoras ${ }^{3}$, algumas das quais já demonstradas mesmo que escassamente, em macrófagos de bovinos ${ }^{1,2,4,5,6,7}$ não tendo sido descritas em bubalinos.

As células da série monócitos/ macrófagos representam a principal população de células ativas na glândula mamária não infectada de bovinos ${ }^{8,9,10} \mathrm{e}$, pela dificuldade em diferenciá-las morfotinturialmente em amostras de leite ${ }^{7}$, por muito tempo foram classificadas como células epiteliais ${ }^{8,9}$, sendo algumas vezes atribuídas a uma nova categoria celular: a dos "macrófagos-células epiteliais" (MCE) $)^{7}$.

A fagocitose pode ser avaliada in vitro, direta ou indiretamente: mensurando a capacidade dos fagócitos englobarem e lisarem partículas ou microrganismos e quantificando a geração dos diversos radicais de oxigênio ou, até mesmo, por avaliação que fora considerado como tentativa 
frustrada de fagocitose, manifestada pela aderência e espraiamento de macrófagos em lamínula de vidro ${ }^{11}$.

Em 1977, Nathan e Root relataram a liberação de $\mathrm{H}_{2} \mathrm{O}_{2}$ por macrófagos ativados. Essa ativação poderia ser induzida in vitro com a utilização de forbol 12-miristrato 13acetato (Phorbol 12-Myristate 13-Acetate PMA), substância estimuladora da "explosão respiratória”, podendo o metabólito ser quantificado, por exemplo, por meio de ensaios envolvendo a oxidação de fenol vermelho dependente de peroxidase ${ }^{11,12,13}$. Esses métodos de avaliação in vitro da atividade dos macrófagos contribuíram de forma marcante para o estudo da interação entre os microrganismos e o hospedeiro, avaliação de tratamentos e diversas condições indutoras de enfermidades em várias espécies de animais ${ }^{14}$. A avaliação da atividade fagocítica de macrófagos lácteos de búfalas possibilitaria verificar a capacidade de resposta imune inata da glândula mamária, níveis de susceptibilidade à mastite, bem como, elucidar a importância que esses mecanismos apresentam em bubalinos.

O presente estudo teve como objetivo avaliar funcionalmente os macrófagos lácteos de búfalas hígidas por meio de testes de fagocitose, espraiamento e liberação de peróxido de hidrogênio.

\section{Materiais e Métodos}

Foram colhidas 56 amostras de leite de 15 búfalas Murrah cujos quartos mamários não apresentavam alterações ao exame físico e o leite era negativo ao CMT e ao exame bacteriológico. Cada amostra foi composta de três alíquotas, a saber: a primeira colhida assepticamente em tubo estéril, refrigerada imediatamente, para exame bacteriológico; a segunda colhida em frasco contendo conservante para contagem automática de células somáticas; a terceira alíquota continha $500 \mathrm{~mL}$ de leite para a recuperação de células e realização de provas foram recuperadas no mínimo $2 \times 10^{6}$ células viáveis/mL e para tal a amostra foi acondicionada em frasco plástico, subseqüentemente filtrada em gaze e transferida para frasco de polipropileno com igual quantidade de PBS (1:1 de leite e PBS). O transporte ao laboratório deu-se em continente isotérmico mantido em gelo picado para que as amostras se mantivessem refrigeradas.

As amostras contendo PBS foram centrifugadas duas vezes (FRC $=450 \mathrm{~g}$, por 20 minutos, à $4^{\circ} \mathrm{C}$ ), desprezou-se o sobrenadante e ressuspendeu-se o sedimento celular ${ }^{15}$. $\mathrm{Na}$ primeira ressuspensão adicionou-se PBS até o volume inicial da amostra e na segunda ressuspensão empregou-se 1,0 $\mathrm{mL}$ de meio enriquecido e pH 6,8 (RPMI 1640a), após o que, procedeu-se a avaliação da viabilidade celular com azul de tripan buscando-se uma concentração mínima de $2 \times 10^{6}$ células viáveis $/ \mathrm{mL}$. Essa suspensão celular também foi utilizada para o exame diferencial após citocentrifugação.

Para o isolamento de leucócitos aderentes objetivando-se obter os índices de fagocitose e espraiamento, utilizou-se placa de poliestireno com 24 poços de $16 \mathrm{~mm}$ de diâmetro, e as lamínulas previamente lavadas e desengorduradas, foram alocadas nos poços e mantidas em fluxo laminar ${ }^{14,16}$. Para cada amostra utilizou-se quatro poços da placa, dois para avaliar a fagocitose e dois para avaliar o espraiamento. Sobre as lamínulas foram depositados 200 iL da suspensão celular contendo $2 \times 10^{6}$ células viáveis/mL, no centro da lamínula. Este sistema foi mantido em temperatura ambiente por 30 minutos e as lamínulas lavadas duas vezes com $1,0 \mathrm{~mL}$ de RPMI 1640 enriquecido com $10 \%$ de soro fetal bovino.

Nas duas linhas inferiores da placa realizou-se o teste de fagocitose adicionandose suspensão de células mortas de Saccaromyces cerevisiae ou zymosan ${ }^{\mathrm{b}}$ por poço. As placas foram incubadas a $37^{\circ} \mathrm{C}$ por uma hora, repetindo-se a dupla lavagem dos poços 
com RPMI 1640, com 10\% soro fetal bovino, evitando-se que a lamínula secasse e danificasse as células. A fixação, após a dupla lavagem, foi feita com glutaraldeído a 0,5\% durante 10 minutos, após o que se adicionou 1,0 mL de água ultrapura ${ }^{c}$. A leitura das lamínulas deu-se por microscopia de contraste de fase, com magnitude de 600x, onde foram contadas 400 células e calculados os valores percentuais de células que espraiaram e que fagocitaram.

A avaliação da liberação de peróxido de hidrogênio baseou-se na oxidação de fenol vermelho dependente de peroxidase, e foi realizada segundo o método colorimétrico ${ }^{12}$, adaptado para microensaio $^{13}$, e posteriormente modificado ${ }^{11,14}$. Para tal, a solução celular contendo $2 \times 10^{6}$ cél/mL, foi ressuspendida em RPMI, centrifugada durante 10 minutos a $450 \mathrm{~g}$, à $4^{\circ} \mathrm{C}$, sendo o sobrenadante desprezado. $\mathrm{O}$ sedimento celular formado foi ressuspendido em $1,0 \mathrm{~mL}$ de solução de fenol vermelho, seqüencialmente diluído compondo novas suspensões que possuíam respectivamente: $0,125 \times 10^{6}$ células $/ \mathrm{mL}$; $0,25 \times 10^{6}$ células $/ \mathrm{mL} ; 0,5 \times 10^{6}$ células $/ \mathrm{mL}$ e $1,0 \times 10^{6}$ células $/ \mathrm{mL}$.

Em placa para microcultura de poliestireno com 96 poços de fundo chato, existem oito poços por coluna. Os poços da primeira coluna receberam 100 ì de solução de fenol vermelho constituindo a prova "em branco". Na segunda e terceira colunas foram colocadas em quadruplicatas, concentrações molares previamente conhecidas de $\mathrm{H}_{2} \mathrm{O}_{2}(0,5 ; 1,0 ; 2,0$ e 4,0 nmoles de $\mathrm{H}_{2} \mathrm{O}_{2} / 100$ ì da Solução de Fenol Vermelho -SFV) para determinar a curva padrão. Nas demais colunas foram adicionadas as respectivas diluições de cada amostra (uma diluição de cada amostra por coluna). Nos quatro poços inferiores desta coluna foram adicionados 10 iL de PMA para ativar as células. Este PMA foi previamente diluído na concentração de $10 \mathrm{mg} / \mathrm{mL}$ de dimetil sulfóxido (DMSO), para a seguir 10 iL desta solução ser diluído C Milli-Q® em 1,0 mL de PBS, para que a concentração correspondesse a 10 ìg de PMA por mL de PBS.

A placa foi fechada e incubada por uma hora a $37^{\circ} \mathrm{C}$, em câmara úmida. Após este período, a reação foi bloqueada pela adição, em cada poço, de 10 iL de solução normal de $\mathrm{NaOH}$, e a absorbância determinada em microleitor automático de ELISA, com filtro de $620 \mathrm{~nm}$ e o resultado expresso em nmoles $/ 2 \times 10^{5}$ células.

Pelo teste estatístico de normalidade de Kolmogorov-Smirnov considerou-se como paramétricas as seguintes variáveis: viabilidade celular, índices de espraiamento e fagocitose, porcentagens de macrófagos/ monócitos, polimorfonucleares neutrófilos, sendo inicialmente analisados pelo teste $\mathrm{F}$ (análise de variância), e quando significativo, as médias confrontadas pelo teste de Duncan, com nível de significância de 5\%. No caso de testes não-paramétricos as variáveis estudadas foram a contagem de células somáticas, a porcentagem de linfócitos e a liberação de peróxido de hidrogênio, e os resultados analisados pelo teste de Mann-Whitney. Calculou-se o coeficiente de correlação de Pearson entre duas variáveis e a sua significância avaliada por meio da análise de variância ${ }^{17}$, utilizandose software MINITAB ${ }^{18}$.

\section{Resultados e Discussão}

O presente estudo foi motivado pela necessidade de compreender a resposta imune inata da glândula mamária de bubalinos, nesse caso, avaliando funcionalmente os macrófagos lácteos oriundos de mamas sadias. A exemplo do que já havia sido descrito em bovinos s, $^{5,7,10}$ e em bubalinos $^{2}$ em trabalho precursor a esse, o macrófago é a célula predominante em leite de mamas hígidas. Em outras palavras, essas células são importantes desde o primeiro contato entre o patógeno e o hospedeiro e suas peculiaridades funcionais manifestas especificamente nesse microambiente poderiam colaborar no entendimento de mecanismos de susceptibilidade à doença. 
As provas empregadas para essa avaliação funcional foram os testes de fagocitose, espraiamento e liberação de peróxido de hidrogênio.

As mamas foram consideradas sadias por não apresentarem alterações ao exame físico e, ao exame do leite, esse material era triado conforme fosse negativo no CMT e no exame microbiológico, provas essas que se repetiram no dia da colheita para assegurar a homogeneidade do grupo e garantir o critério de inclusão amostral.

Quanto à celularidade do leite, a mediana do número de células somáticas foi de 14.500 células / $\mathrm{mL}$. No exame diferencial, os linfócitos apresentaram uma mediana de $4,33 \%$ e as médias e desvios padrão dos valores relativos percentuais de monócitos/ macrófagos e dos polimorfonucleares neutrófilos foram respectivamente 50,77\% $\pm 18,28$ e $32,13 \% \pm 19,27$, confirmando o predomínio de macrófagos (Figura1) nesse material ${ }^{15}$. Os polimorfonucleares eosinófilos e demais células, não foram identificados nas amostras analisadas pela técnica empregada.

As amostras apresentaram baixas contagens, menores que as encontradas em estudos abordando macrófagos lácteos de vacas sadias ${ }^{2,6}$. Outra particularidade foi a de que no que concerne a células de bovinos, há a preocupação com a possibilidade da baixa celularidade representar aumento do risco de mastite, principalmente quando os animais são mantidos em condições higiênico-sanitárias controladas. As búfalas desse estudo pertenciam a rebanhos comuns, com ordenha manual, sem realização de imersão em anti-séptico no final da ordenha (pós-dipping), tratamento com antimicrobianos no período de secagem e com açudes para que os animais imergissem representando potencial fonte de infecção. Apesar de todos esses fatores que predisporiam os bovinos à mastite, nos bubalinos não se identificou dificuldade em obter amostras sem crescimento bacteriano, além de não se observar qualquer animal com alterações físicas de processo inflamatório agudo da glândula mamária durante o experimento. Muito pelo contrário, a maior dificuldade foi atingir a concentração necessária de células viáveis para a execução das provas funcionais não aparentando ser a baixa contagem um fator de aumento de susceptibilidade dessas mamas.

Para que esta pesquisa fosse realizada, foram necessárias adaptações a recuperação das células presentes no leite, após o que, utilizaram-se as técnicas adaptadas para macrófagos alveolares de eqüinos ${ }^{14}$. A viabilidade média das células das amostras foi de $66,8 \% \pm 15,8$. Dentre os parâmetros funcionais, o índice de espraiamento e de índice de fagocitose foram $30,1 \% \pm 16,9$ e $58,5 \% \pm 13,3$, respectivamente. Não houve diferença entre a liberação espontânea (sem estímulo do PMA) e induzida (com estímulo do PMA) (Tabela 1).

O espraiamento é prova de função definida por Russo et al. ${ }^{11}$ como tentativa frustrada de fagocitose. Todavia, nesse tipo de avaliação na qual não há substrato disponível para fagocitar, nada há com que se frustrar. Seria mais apropriado sugerir que essa célula está apta a exercer suas funções e em atividade responsiva manifestando a característica, de se aderir à lâmina e emitir microvilos (Figura 2).

Poucos trabalhos estudaram especificamente os macrófagos do leite, e quando o fizeram, empregaram leite de bovinos ${ }^{2,4,5,6}$. Os únicos autores, que empregaram a avaliação do espraiamento, foram Desiderio e Campbell ${ }^{5}$ cujo objetivo era identificá-los no leite para empregá-los experimentalmente, substituindo alternativas mais invasivas como as empregadas em animais de laboratório. Esses autores relataram a capacidade de espraiamento dessas células "nonelicited" como verificado nesse estudo e consideraram como positiva a possibilidade de trabalhar com uma célula "nonelicited" por esta condição estar mais próxima da condição natural.

Nesse estudo, empregando amostras "nonelicited", avaliaram-se amostras de leite sem indícios de inflamação e de infecção, cujo único estímulo foi aplicado in vitro. 
Tabela 1 - Índices de fagocitose, de espraiamento e liberação de peróxido de hidrogênio com e sem estimulação in vitro de células do leite de búfalas hígidas. São Paulo, 2002

\begin{tabular}{ccccc}
\hline & Fagocitose & Espraiamento & \multicolumn{2}{c}{ Liberação de $\mathrm{H}_{2} \mathrm{O}_{2}$} \\
\hline & $(\%)$ & $(\%)$ & $\begin{array}{c}\text { Sem PMA } \\
\text { (nmoles/2x } 10^{5} \\
\text { células) }\end{array}$ & $\begin{array}{c}\text { Com PMA (nmoles/2x } \\
10^{5} \text { células) }\end{array}$ \\
\hline Mediana & 59,5 & 30,0 & $6,20^{\text {a }}$ & $7,74^{\text {a }}$ \\
Média & 58,5 & 30,1 & $9,67^{\text {a }}$ & $11,47^{\text {a }}$ \\
Desvio & 13,3 & 16,9 & 8,95 & 10,75 \\
padrão & 22,7 & 56,1 & 92,5 & 93,7 \\
CV (\%) & 56 & 56 & 20 & 20 \\
$N^{*}$ & & & &
\end{tabular}

Letras iguais na mesma linha indicam resultados semelhantes, p>0,5. CV: coeficiente de variação

Tabela 2 - Relações entre as diversas provas funcionais e populações leucocitárias analisadas na suspensão celular de leite de búfalas sadias - São Paulo- 2002

\begin{tabular}{|c|c|c|c|c|}
\hline & Espraiamento & Fagocitose & $\begin{array}{c}\mathrm{H}_{2} \mathrm{O}_{2} \\
\text { com PMA }\end{array}$ & $\begin{array}{c}\mathrm{H}_{2} \mathrm{O}_{2} \\
\text { sem PMA }\end{array}$ \\
\hline $\begin{array}{c}\mathbf{N}^{0} \text { de células } \\
\text { somáticas }\end{array}$ & $\mathbf{N S}$ & NS & NS & NS \\
\hline Monócito/Macrófago & $\mathbf{N S}$ & $\mathbf{N S}$ & NS & $\mathbf{N S}$ \\
\hline $\begin{array}{c}\text { Polimorfonucleares } \\
\text { Neutrófilo }\end{array}$ & NS & NS & $\begin{array}{c}r=-0,440 \\
p<0,04\end{array}$ & $\begin{array}{c}r=-0,463 \\
p<0,04\end{array}$ \\
\hline Linfócito & NS & $\begin{array}{l}r=0,449 \\
p<0,04\end{array}$ & NS & $\mathbf{N S}$ \\
\hline Espraiamento & - & $\begin{array}{l}r=0,463 \\
p<0,03\end{array}$ & $\begin{array}{c}r=-0,521 \\
p<0,02\end{array}$ & $\begin{array}{c}r=-0,543 \\
p<0,01\end{array}$ \\
\hline Fagocitose & $\begin{array}{l}r=0,463 \\
p<0,03\end{array}$ & - & NS & NS \\
\hline $\mathrm{H}_{2} \mathrm{O}_{2}$ com PMA & $\begin{array}{c}r=-0,521 \\
p<0,02\end{array}$ & NS & - & $\begin{array}{c}r=0,995 \\
p<0,0001\end{array}$ \\
\hline $\mathrm{H}_{2} \mathrm{O}_{2}$ sem PMA & $\begin{array}{l}r=-0,543 \\
p<0,01\end{array}$ & NS & $\begin{array}{c}r=0,995 \\
p<0,0001\end{array}$ & - \\
\hline
\end{tabular}

NS = não signiticativa

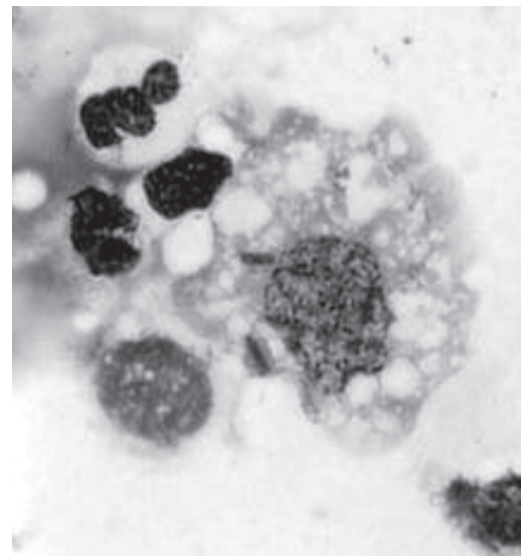

Figura 1 - Macrófago vacuolizado (A), neutrófilo (B), em coloração de Rosenfeld e aumento de 600x

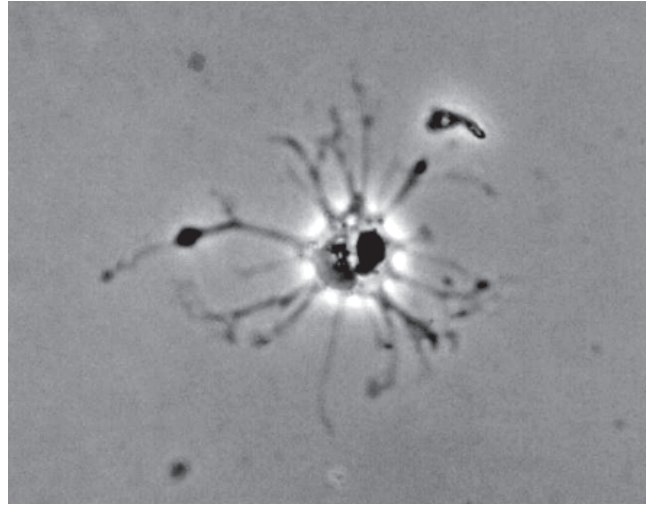

Figura 2 - Fotomicrografia de macrófago de leite de búfala, aderido e espraiado in vitro, com projeções (A) e vacúolos citoplasmáticos (B). Microscopia de contraste de fase, aumento de $600 x$ 


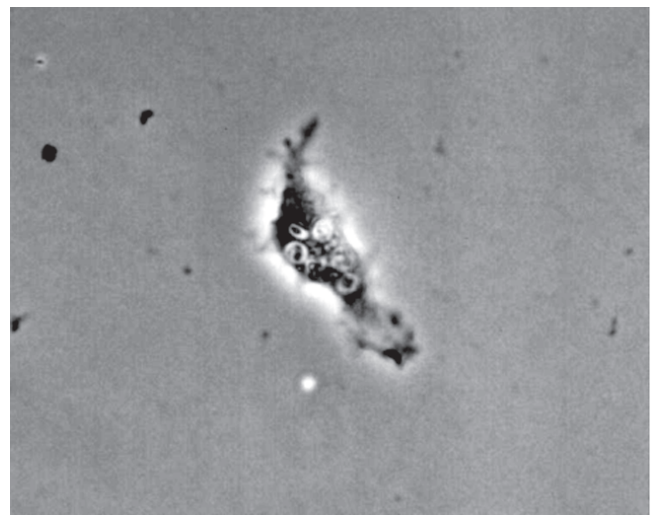

Figura 3 - Fotomicrografia de macrófago de leite de búfala, aderido in vitro, com partículas de zymosan no interior do citoplasma indicando fagocitose (A). Microscopia de contraste de fase, aumento de $600 x$

Apesar disso, obteve-se valores superiores aos anteriormente descritos ${ }^{5,16}$, e as alterações morfológicas (Figura 2) observadas foram semelhantes ${ }^{5,14}$ às citadas em outras espécies, com dois tipos principais de extensões celulares, os pseudópodos pequenos ou microfilamentos e longos microfilamentos terminais de fixação ${ }^{5}$.

Os macrófagos lácteos "nonelicited" fagocitaram partículas de zymosan, independentemente de opsoninas (Figura 3). De todas as análises, a determinação dos índices de fagocitose demonstrou menor coeficiente de variação, corroborados pela correlação positiva entre os índices de fagocitose e espraiamento. Quando correlacionado às diferentes populações de leucócitos quantificadas na citologia, o índice de fagocitose só manifestou correlação com os valores percentuais de linfócitos, sugerindo uma relação entre as funções celulares, já descrita em bovinos, de apresentação de antígeno ${ }^{2}$ e microbicidas ${ }^{7}$.

Nos ensaios para mensuração da liberação de $\mathrm{H}_{2} \mathrm{O}_{2}{ }^{14}$, observou-se que os macrófagos lácteos "nonelicited" mostraram atividade, independentemente da adição de PMA (Tabela 1). Nessa análise três aspectos são passíveis de discussão.

O primeiro aspecto seria a alta liberação de $\mathrm{H}_{2} \mathrm{O}_{2}$ que, inclusive tornou necessário trabalhar com a amostra dividida em diferentes concentrações celulares, adaptando a técnica ${ }^{12,13,14}$. Em outras palavras, uma amostra permitia a leitura com uma concentração celular de 1 X $10^{6}$ céls/ $\mathrm{mL}$ enquanto outra, mesmo tendo origens semelhantes (mama hígida), só apresentou uma liberação dentro do intervalo da curva (intervalo entre 0,5 e 4,0 nmoles de $\mathrm{H}_{2} \mathrm{O}_{2} /$ $100 \mathrm{ml}$ de SFV), com uma concentração de $0,25 \times 10^{6}$ céls $/ \mathrm{mL}$, confirmando a acentuada variação individual.

$\mathrm{O}$ segundo aspecto seria a ausência de diferença de atividade em presença do PMA, que apesar de diferir da proposta inicial do ensaio ${ }^{12,13}$, já havia sido descrita antes em outros modelos "nonelicited" que não envolviam macrófagos lácteos ${ }^{14}$. A falta de diferença na liberação de $\mathrm{H}_{2} \mathrm{O}_{2}$ com e sem estímulo de PMA pode significar que a liberação espontânea dos fagócitos do leite de búfalas hígidas seria mantida no limite máximo e, portanto indiferente ao estímulo do PMA.

O terceiro aspecto seria o fato de terem sido utilizadas amostras contendo várias populações de células, diferentemente do ocorrido nas demais provas funcionais empregadas $^{7}$ e, mesmo assim não ter sido descrita correlação entre população celular e liberação de $\mathrm{H}_{2} \mathrm{O}_{2}$ (Tabela 2). Os altos valores de liberação de peróxido de hidrogênio deverão ser atribuídos tanto aos macrófagos como aos neutrófilos presentes na suspensão celular.

Não houve correlação entre contagem de células somáticas e as demais variáveis funcionais. Já as correlações com os diferentes tipos celulares apresentaram variações. A correlação negativa com os valores percentuais de neutrófilos talvez tenha ocorrido pela já citada independência entre a quantidade dos neutrófilos e a qualidade da atividade dos mesmos tornando possível a hipótese de, em mamas sadias com menos PMN talvez pela ausência de estímulo para que essas células fossem para o leite, as poucas células presentes garantiriam uma resposta basal mais acentuada. A ausência de correlação entre a população de macrófagos e as provas 
funcionais é explicada pela diversidade funcional dos macrófagos que são encontrados no leite em toda a série monócito-macrófago ${ }^{4}$.

Por outro lado, os índices de espraiamento considerados correspondentes à ativação macrofágica, apresentaram correlação positiva com a fagocitose e com os valores percentuais de linfócitos, células essas também envolvidas nos processos de ativação ${ }^{9,10}$. Houve correlação negativa do espraiamento com a liberação de peróxido de hidrogênio. Esse último resultado pode significar que quanto mais ativado menor a liberação de peróxido de hidrogênio. Ao contrário das provas de fagocitose e de espraiamento que trabalham exclusivamente com as células com propriedade de aderência ao vidro, predominantemente macrófagos, na avaliação da liberação de peróxido de hidrogênio a população da suspensão celular era heterogênea e a liberação não poderia ser atribuída apenas aos macrófagos apesar de predominantes.

As técnicas para a determinação dos índices de espraiamento, fagocitose e liberação de peróxido de hidrogênio se mostraram factíveis em células provenientes do leite de búfalas hígidas, "nonelicited" e padronizadas para diferentes aplicações.

\section{Conclusões}

Os macrófagos expressaram as funções testadas a saber, espraiamento, fagocitose e liberação de peróxido de hidrogênio. Esse último mecanismo demonstrou ser o metabolismo oxidativo extremamente ativo em búfalas e com significativa variação individual.

\title{
Milk macrophages from healthy female buffaloes: evaluation of phagocytosis test, spreading and hydrogen peroxide release assays
}

\begin{abstract}
The objective of the present study was to evaluate the functioning of nonelicited dairy macrophages present in phagocytosis, spreading and hydrogen peroxide release tests. Fifty-six samples of milk were collected from 15 healthy buffaloes. Total and differential somatic cell counts, cell viability, and indexes of phagocytosis, spreading and hydrogen peroxide release were assessed. The following values were obtained: mean of 14,500 cells $/ \mathrm{mL}$ of milk, with median equal to $4.33 \%$ of lymphocytes; mean and standard deviation equal to $50.77 \%+18.28$ of monocytes / macrophages and $32.13 \%+19.27$ polymorphouclear cells. Mean viability of cells in suspension was $66.8 \%+15.8$; phagocytosis and spreading indexes were equal to $30.1 \%+16.9$ and $58.5 \%+13.3$, respectively. There was no difference between the spontaneous release of $\mathrm{H}_{2} \mathrm{O}_{2}$ and the one induced by PMA. It was concluded that nonelicited macrophages present in the milk of healthy buffaloes were significantly capable to spread and phagocyte. Phagocytes presented the ability to release hydrogen peroxide either spontaneously or not, in a maximum level and with a significant variation between samples.
\end{abstract}

\section{Referências}

1 INTERNATIONAL DAIRY FEDERATION. Ruminant mammary gland immunity. Brussels: International Dairy Federation, 2003. p. 10-13.

2 POLITIS, I.; ZHAO, X.; MCBRIDE, B. W.; BURTON,
J. H. Function of bovine mammary macrophages as antigen-presenting cells. Veterinary Immunology and Immunopathology, v. 30, p. 399-410, 1992.

3 ELGERT, K. D. Immunology. Understanding the immune system. Wiley-Less, 1996.

4 CONCHA, C.; HOLMBERG, O. Ability of bovine mammary macrophages to enhance proliferation of 
autologous blood and mammary secretion lymphocytes. Journal of Dairy Research, v. 57, p. 7-16, 1990.

5 DESIDERIO, J. V.; CAMPBELL, S. G. Bovine mammary gland macrophage: isolation, morphologic features, and cytophilic immunoglobulins. American Journal Veterinary Research, v. 41, n. 10, p. 1595-1599, 1980.

6 POLITIS, I.; MCBRIDE, B. W.; BURTON, J. H.; ZHAO, X.; TURNER, J. D. Secretion of interleukin-1 by bovine milk macrophages. American Journal Veterinary Research, v. 52, n. 6, p. 858-862, 1991.

7 SANDGREN, C. H.; NORDLING, K.; BJÖRK, I. Isolation and phagocytic properties of neutrophils and other phagocytes from nonmastitic bovine milk. Journal of Dairy Science, v. 74, p. 2965-2975, 1991.

8 JENSEN, D. L; EBERHART, R. J. Total and differential cell counts in secretions of the nonlactating bovine mammary gland. American Journal Veterinary Research, v. 42, p. 743-747, 1981.

9 LEE, C.; WOODING, F. B.; KEMP, P. Identification, properties, and differential counts of cell populations using microscopy of dry cows secretions, colostrum and milk from normal cows. Journal of Dairy Research, v. 47, p. 39-50, 1980.

10 ÖSTENSSON, K. Trafficing of leukocytes and immunoglobulin isotypes in the bovine udder. Studies of milk, lymph and blood from cows with healthy and mastitic mammary glands. 1993. 67 p. Tese (Doctor) Faculty of Veterinary Medicine, Swedish University of Agricultural Sciences, Uppsala, Sweden, 1993.

11 RUSSO, M. et al. Superoxide-independent hydrogen peroxide release by activated macrophages. Brazilian Journal Medical Biological Research, v. 22, n. 10, p. 1271-1273, 1989.

12 PICK, E.; KEISARI, Y. A simple colorimetric method for the measurement of hydrogen peroxide produced by cells in culture. Journal of Immunological Methods, v. 38, n. 1-2, p. 161-70, 1980.

13 PICK, E.; MIZEL, D. Rapid microassays for measurement of superoxide and hydrogen peroxide production by macrophages in culture using an automatic enzyme immunoassay reader. Journal of Immunology Methods, v. 46, n. 2, p. 211-226, 1981.

14 MORI, E.; MORI, C. M. C.; DELLA LIBERA, A. M. M. P.; LARA, M. C. C. S. H.; FERNANDES, W. R. Evaluation of alveolar macrophage function after experimental infection with equine herpesvirus- 1 in horses. Arquivos Brasileiros de Medicina Veterinária e Zootecnia, v. 55, n. 3, p. 271-278, 2003.

15 DELLA LIBERA, A. M. M. P.; ARAUJO, W. P.; KITAMURA, S. S.; ROSENFELD, A. M. F.; BIRGEL, E. H. Citologia do leite de búfalas (Bubalus bubalis) hígidas criadas no Estado de São Paulo, Brasil. Ciência Rural, v. 34, n. 4, p. 1087-1092, 2004.

16 RABINOVITCH, M.; De STEFANO, M .J.
Macrophage spreading in vitro I. Inducers of spreading. Experimental Cell Research, v. 77, p. 323-324, 1973.

17 SNEDCOR, G. W.; COCHRAN, W. G. Statistical methods. 6 ed. Ames: lowa State University press, 1967. $593 \mathrm{p}$.

18 MINITAB - The Student Edition of MINITAB Statistical software adapted for education - 13.0 Release. User's Manual. New York: Addison - Wesley, 2000. 